\title{
SINERGIA
}

REVISTA DO INSTITUTO DE CIÊNCIAS ECONÔMICAS, ADMINISTRATIVAS E CONTÁBEIS (ICEAC)

\section{PRECISAMOS FALAR SOBRE ATIVO: ANÁLISE DA PERCEPÇÃO DISCENTE A PARTIR DA TEORIA DO SIGNO LINGUÍSTICO DE SAUSSURE}

\author{
LIEGE MORAES \\ JOÃO PAULO RESENDE DE LIMA" \\ JULIANA BITTAR-GODINHO** \\ VINÍCIUS MOTHÉ MAIA****
}

\section{RESUMO}

Este trabalho investiga a percepção dos graduandos em Contabilidade sobre o conceito de ativo, sob a perspectiva teórica saussureana. Distribuiu-se questionário adaptado de Goulart (2002), obtendo amostra composta por 185 graduandos em Ciências Contábeis de cinco Instituições de Ensino Superior (IES), localizadas na cidade de São Paulo. Os dados foram analisados de forma descritiva, realizando-se, também, a Análise de Correspondência Simples (ANACOR). Resultados apontam confusão entre significado e significante de acordo com a Teoria do Signo Linguístico de Saussure. Porém, é possível observar mudanças na percepção do conceito entre a amostra de Goulart e a deste artigo. A característica "benefícios econômicos futuros" se destaca como uma das principais para os estudantes. Portanto, espera-se contribuir teoricamente no entendimento sobre o conceito de ativo a partir da perspectiva linguística. Contribui com empresas, mercado e governo, incentivando formação de contadores baseada em princípios e julgamento profissional, e não apenas em regras. Para as IES, incentiva um currículo que aproxime signo de significante, aproximando ensino de teoria e prática. Por fim, contribui à prática docente com informações sobre principais confusões conceituais sobre o conceito de ativo.

Palavras-chave: Educação contábil; Perspectiva discente; Teoria do Signo Linguístico de Saussure; ativo; Análise de Correspondência Simples.

\section{ABSTRACT}

This work investigates the perception of undergraduate students in Accounting on the asset concept, under the Saussurean theoretical perspective. We distributed an adapted questionnaire from Goulart (2002), obtaining a sample composed of 185 undergraduate students in Accounting Sciences from five Higher Education Institutions (HEls) located in São Paulo. The data were analyzed descriptively, also performing the Simple Correspondence Analysis (ANACOR). Results point out the confusion between meaning and signifier, according to Saussure's Theory of Linguistic Signs. However, it is possible to observe changes in the perception of Goulart's sample and that of this article. The "future economic benefits" feature stands out as one of the main ones for students. Therefore, we hope the study contributes theoretically to understanding the asset concept from a linguistic perspective. It contributes to companies, the market, and the government by encouraging accountants' training based on principles and professional judgment, not just on rules. For HEls, it encourages a curriculum that brings the sign closer to the signifier, bringing theory and practice closer together. To the teaching practice, it contributes to information about the main conceptual confusions about the asset concept.

Keywords: accounting education; student perspective; Saussure's Linguistic Sign Theory; active; Simple Correspondence Analysis.

Recebido em: 30-03-2021 Aceito em: 25-06-2021

\section{INTRODUÇÃO}

Pesquisas anteriores, no Brasil, investigaram a percepção sobre os conceitos fundamentais da Contabilidade lecionados durante a disciplina de Teoria da Contabilidade sob a óptica discente (LIMA FILHO;

\footnotetext{
"Doutoranda em Controladoria e Contabilidade pela Universidade de São Paulo (USP). Mestre em Ciências Contábeis pela Universidade Federal do Rio de Janeiro (2015). E-mail: liegemoraes@usp.br

"* Doutorando em Controladoria e Contabilidade pela Universidade de São Paulo (USP). Mestre em Controladoria e Contabilidade pela Faculdade de Economia, Administração e Contabilidade de Ribeirão Preto da Universidade de São Paulo (FEA-RP/USP).

*** Doutora e Mestre em Administração de empresas pela Faculdade de Economia e Administração - FEA-USP. Bacharel em Relações Internacionais pela UNESP.

Doutor em Administração de Empresas pela Pontifícia Universidade Católica do Rio de Janeiro (2018). Mestre em Administração de Empresas pela Pontifícia Universidade Católica do Rio de Janeiro (2012). Docente da Universidade Federal do Rio de Janeiro (UFRJ).
} 
BRUNI, 2012; PICCOLI; CHIARELLO;KLANN, 2015; SOUZA; VICENTE, 2017; SANTOS; FREITAS;DIAS FILHO, 2020), sob a óptica docente (CUNHA; GUIDINI; KLANN, 2017), bem como sobre conteúdos de planos de ensino da referida disciplina em programas de pós-graduação em Contabilidade (BORBA; POETA; VICENTE, 2011; IUDÍCIBUS; BEUREN; SANTOS, 2016). Nenhum destes estudos investigou especificamente o "ativo", um dos conceitos fundamentais da Contabilidade e seu entendimento. O ativo é "o capítulo fundamental da Contabilidade, porque a definição e mensuração dele está ligada à multiplicidade de relacionamentos contábeis que envolvem receitas e despesas" (IUDICIBUS, 2000 p. 157). Contudo, a academia contábil brasileira é carente em trabalhos com foco exclusivo no conceito.

As teorias são fruto e reflexos da realidade social, econômica e patrimonial na qual se inserem. Assim, o próprio conceito de "ativo" sofreu diversas alterações teóricas e práticas no decorrer da história da Contabilidade (MARTINEZ et al., 2017). Além disso, utiliza-se o termo "conceito" e não "definição", aludindose ao "conceito" ser uma ideia sem forma fixa consensual entre toda uma comunidade de pensadores, já a "definição", sim. Então, considera-se "ativo" o conceito da Ciência Contábil, dependente de sua respectiva interação com o meio para manifestar-se.

Assim, o estudo de conceitos para a Contabilidade como ciência social aplicada é indispensável. Podese citar, por exemplo, o processo de convergências às Normas Internacionais de Contabilidade (IFRS), cuja proposta é a realização da Contabilidade com base em princípios. Dantas, Rodrigues, Niyama e Mendes (2010, pp. 8-9) explicam: "o pressuposto é: as normas baseadas em princípios não determinam como fazer, mas sim como decidir o que necessita ser feito". Ou uma Contabilidade fundamentada em princípios, não em regras, requer sólida e profunda formação de conhecimentos basilares do contador, porque o exercício de sua profissão estará alicerçado em julgamento profissional.

Dentre as possibilidades teóricas para análise de conceitos, adotou-se a Teoria do Signo Linguístico de Saussure, que separa todo signo em duas partes: significado, o conceito propriamente dito, e significante, a impressão psíquica ou imagem acústica do significado (SAUSSURE, 2006). A escolha de tal teoria baseiase em sua importância histórica, porquanto o trabalho de Saussure foi base para estudos teóricos de áreas ligadas à linguagem como: Claude Lévi-Strauss, Jacques Lacan e Michel Foucault (MACINTOSH, 2002). Escolheu-se a Teoria do Signo Linguístico pelo potencial de contribuir para um melhor entendimento acerca do conceito de ativo, pois, para ela, todo signo é produto das relações humanas (DEELY, 1990). Assim, todo signo é histórico, socialmente localizado e construído, sendo a Contabilidade uma ciência social aplicada (DILLARD; VINNARI 2019).

Assim, este trabalho analisará a percepção dos estudantes de graduação em Contabilidade acerca do conceito de ativo a partir da semiótica Saussuriana. O trabalho justifica-se diante da importância do conceito de ativo para a Contabilidade e é reforçado pelo fato de profissionais atuantes, na área contábil, apresentarem dificuldade na compreensão deste conceito. Goulart (2002) constatou não haver a demonstração pelos respondentes de "compreensão sobre a essencialidade da noção de benefícios futuros para a caracterização da natureza básica dos ativos" (GOULART, 2002, p. 56).

Os graduandos atuais serão os futuros profissionais e pesquisadores/docentes da área. Portanto, analisar sua percepção sobre ativo pode trazer novos insights sobre o futuro do campo, além de refletir como tal conceito é recebido em sala de aula. Enfim, destaca-se que Goulart (2002) desenvolveu seu trabalho anteriormente à adoção das IFRS.

Para alcançar o objetivo da pesquisa, utilizou-se questionário desenvolvido por Goulart (2002), com adaptações, cuja motivação eram os conhecimentos superficiais dos profissionais de Contabilidade e as áreas afins sobre o conceito de "ativo". A amostra contém respostas de 185 graduandos em Ciências Contábeis de cinco Instituições de Ensino Superior (IES), localizadas na cidade de São Paulo, sendo uma pública e quatro privadas.

Os resultados apontam confusão entre significado e significante de acordo com a Teoria dos Signos de Saussure. Apesar disso, já é possível observar mudanças na percepção entre a amostra de Goulart e a deste artigo. A característica "benefícios econômicos futuros" se destaca como uma das principais para os estudantes. Logo, espera-se contribuir teoricamente para melhorar o entendimento do conceito de ativo. Para as IES, dará subsídios para uma formação que aproxime signo de significante, aproximando ensino de teoria e prática. Contribuirá, também, com a prática docente, informando sobre confusões conceituais. A seguir, trataremos dos aportes teóricos desta pesquisa.

\section{TEORIA DO SIGNO LINGUÍSTICO}

A Teoria do Signo Linguístico de Ferdinand de Saussure é vista como um marco para a linguística moderna, sendo seu maior mérito o caráter metodológico, pois os linguistas, antes de Saussure, tratavam coisas diferentes com nomes iguais (CARVALHO, 2013). Uma das principais críticas de Saussure aos estudos linguísticos precedentes era a noção de língua como simples nomenclatura para designar uma lista de termos correspondentes às coisas, dado "que supõe ideias completamente feitas, preexistentes às palavras [...] 0 
que está bem longe da verdade" (SAUSSURE, 2006, p. 79).

$\mathrm{Na}$ concepção saussureana, a língua é um conjunto de signos linguísticos, socialmente cristalizados pela prática da fala de indivíduos de uma mesma sociedade. Em sua concepção, a língua falada e a língua escrita são dois sistemas distintos de signos, sendo que a única razão de existir a língua escrita é para representar a língua falada. Saussure afirma: "a palavra escrita se mistura tão intimamente com a palavra falada, da qual é a imagem, usurpando-lhe o papel principal; terminamos por dar maior importância à representação do signo vocal do que ao próprio signo" (SAUSSURE, 2006, p. 34).

Além da contribuição para a definição de "língua" e da separação entre os sistemas da língua falada e da língua escrita, outra contribuição de Saussure (2006) é o aprofundamento da discussão acerca da formação do signo linguístico (COLLADO, 1980; DUBOIS; GIACOMO; GUESPIN; MARCELLESI; MARCELLESI; MEVEL, 1998; CARVALHO, 2013). O signo linguístico é entidade psíquica, não une uma coisa a uma palavra, mas sim um conceito a uma imagem acústica (SAUSSURE, 2006).

Assim, Saussure (2006) afirma que as pessoas esquecem essa totalidade do signo linguístico e acabam por reduzi-lo a uma de suas partes, à imagem acústica. Para superar essa ambiguidade, o autor propõe chamarmos "as três noções aqui presentes [signo, conceito e imagem acústica] por nomes que se relacionem entre si, ao mesmo tempo que se opõem" (SAUSSURE, 2006, p. 81). O autor propõe a manutenção do signo para designar o todo, contudo sugere que conceito e imagem acústica sejam substituídas por significado e significante, respectivamente.

Partindo dessa substituição, pode-se afirmar que significante é a palavra falada ou escrita, assim como som/imagem, enquanto significado é sua outra parte e é representada pela imagem invocada na nossa mente. Macintosh (2002) ressalta a adoção pelo signo linguístico como referencial a um objeto real existente ou a um ideal fora do sistema semiótico. Para ilustrar o sistema teórico proposto por Saussure, Macintosh (2002) apresenta a Figura 1.

Figura 1 - Esquema teórico da Teoria do Signo Linguístico

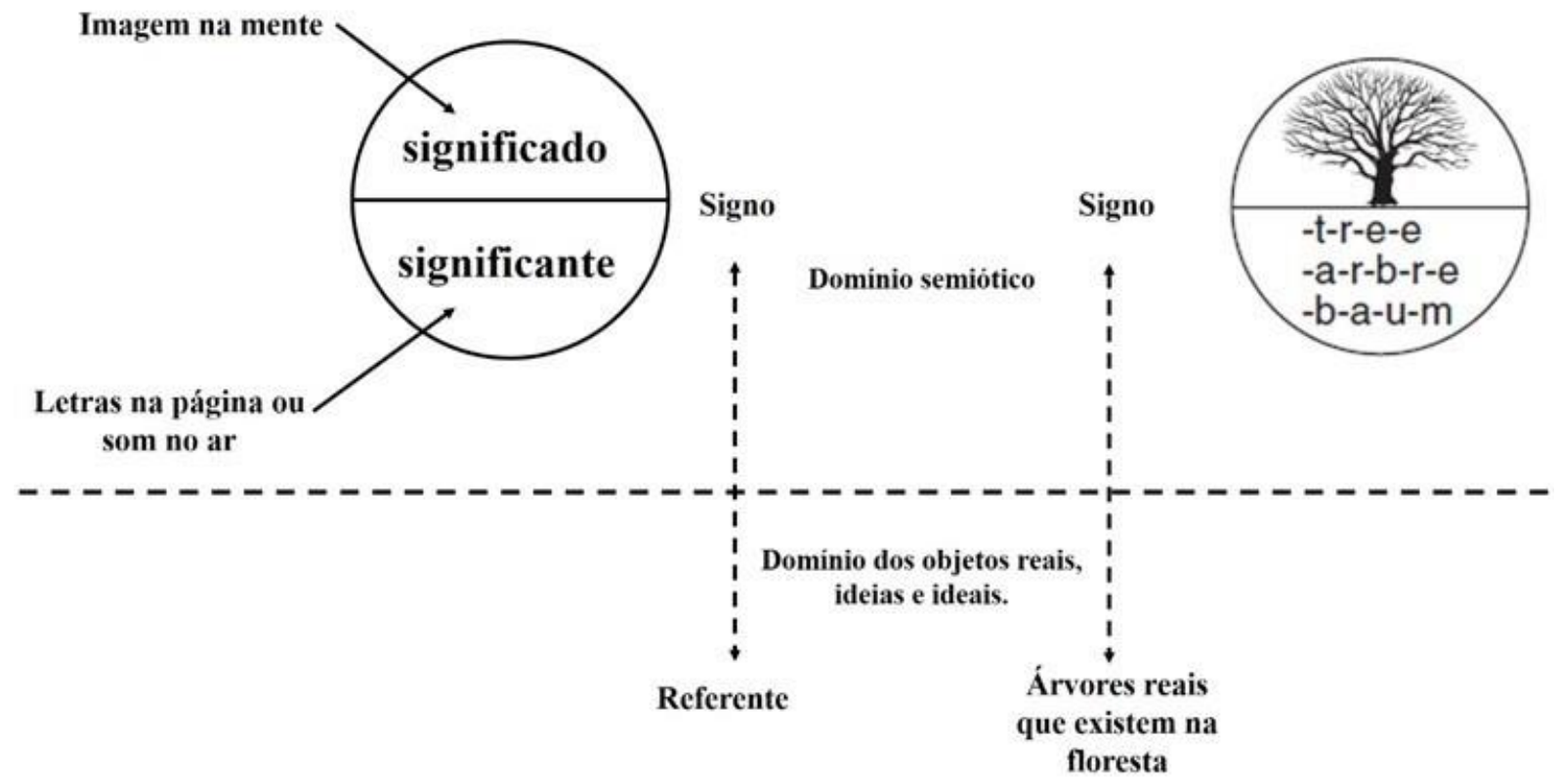

Fonte: Adaptado de Macintosh (2002, p. 11)

Partindo da definição do signo linguístico como a união do significado e significante, Saussure propõe que todo signo possui três princípios. O primeiro princípio afirma que o laço entre significante e significado é arbitrário, ou o signo linguístico é arbitrário. Para exemplificar esse princípio, Saussure afirma que a ideia de "mar" não está ligada à sequência de sons "m-a-r", funcionando como significante, dado que a ideia de "mar" poderia ser representada de outra maneira. Também, a palavra "boi", na língua francesa, tem como significante boeuf na fronteira franco-germânica, e ochs, do outro lado da fronteira. O segundo princípio do signo linguístico é o caráter linear, visto que o significante possui natureza auditiva e desenvolve-se temporalmente. Por fim, o terceiro princípio é de imutabilidade e mutabilidade do signo. Afirma: "[s]e, com relação à ideia representada, o significante aparece como escolhido livremente, mas, em compensação com relação à comunidade linguística que o emprega, não é livre: é imposto" (SAUSSURE, 2006, p. 85). Tal princípio é devido à língua sempre aparecer como herança de eras precedentes, adotando caráter histórico e social.

A partir da Teoria do Signo Linguístico Saussureana, observou-se a arbitrária e a baixa cientificidade 
relação entre significado e significante. Assim, concluiu-se que o significado das palavras é socialmente construído, conforme uma comunidade histórica e socialmente localizada (MACINTOSH, 2002). Tal conclusão serviu de base para o desenvolvimento e aprofundamento de trabalhos de outros teóricos, assim como das linhas de pesquisa de semiótica e análise do discurso. Especificamente na Contabilidade, Roberts e Wang (2019) utilizam a Teoria do Signo Linguístico para criticar o pressuposto de representação fidedigna, independente dos fatos econômicos, como esperado pelos órgãos reguladores.

Conforme o terceiro princípio do signo (SAUSSURE, 2006), é importante entender como o conceito de ativo constituiu-se e reconstituiu-se ao longo da história. Nesse sentido, ludicibus (2000) afirma que o conceito de ativo passou por um longo processo evolutivo. Dessa maneira, é possível observar, na Figura 2, conforme Martins (1972), que existiram duas visões concorrentes sobre o ativo, uma influenciada pelo foco jurídico de Anthony (1970), com foco na posse dos recursos - e outra pelo foco econômico - a de Sprouse e Moonitz (1962) -, com foco nos benefícios econômicos esperados.

Figura 2 - Evolução do conceito de ativo - autores internacionais

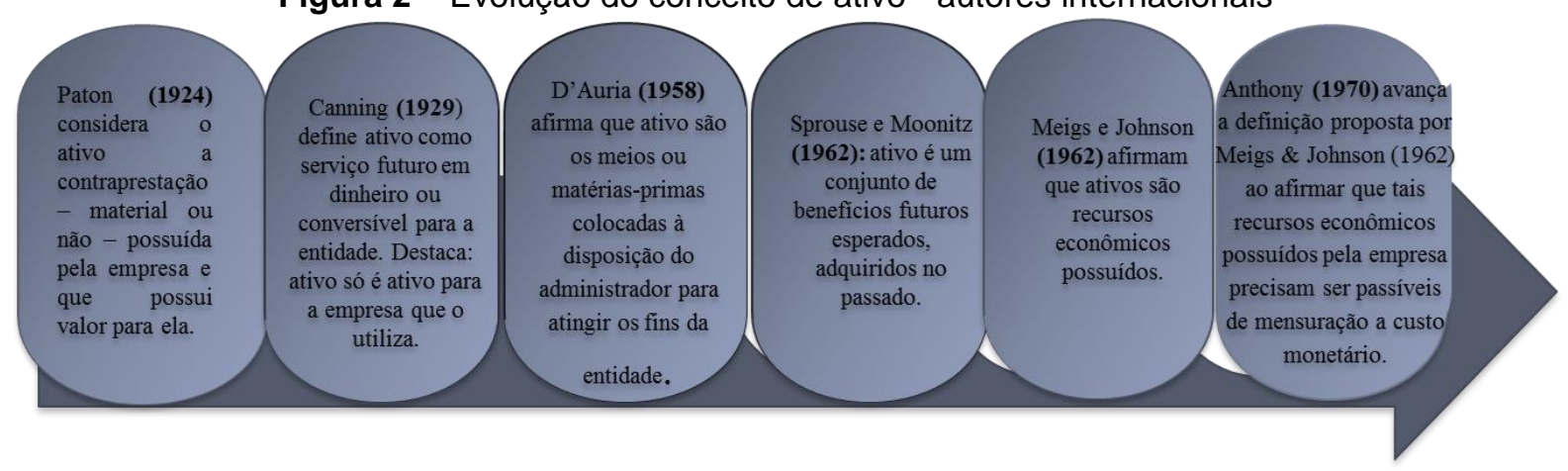

Fonte: Adaptado de ludicibus (2000)

Nacionalmente, o primeiro conceito de ativo é encontrado na década de 1970, proposto por Martins (1972), definido como um conjunto de benefícios futuros provocados por um agente. Semelhantemente, o International Accounting Standards Board, em 2018 (IASB, 2018), revisou a proposta de conceito de ativo e afirma ser um recurso econômico controlado pela entidade como resultado de eventos passados. Tal recurso econômico é um direito com potencial de produzir benefícios econômicos. Portanto, observa-se que existem três elementos em comum compondo o delineamento do conceito de ativo: resultado de eventos passados, geração de benefícios futuros e controle pela entidade (MARTINEZ et al., 2017).

\section{PROCEDIMENTOS METODOLÓGICOS}

A pesquisa é descritiva, com abordagem quantitativa e exploratória. Como procedimentos de pesquisa, utilizou-se levantamento de dados, via distribuição de questionários. O questionário utilizado baseia-se no trabalho de Goulart (2002), com temática acerca do conceito de ativo. Adicionou-se ao questionário uma pergunta sobre o conceito de ativo abordado em Martins (1972). A pergunta questionava sobre o nível de concordância acerca do conceito de ativo ser "o resultado econômico futuro que se espera obter de um agente" (MARTINS, 1972, p. 68).

Assim, o questionário aplicado dividiu-se em duas partes: a primeira, conceitual, e a segunda, qualificadora da amostra. A primeira era formada por quatro questões conceituais acerca do tema de ativo. As questões 1 e 4 versavam sobre nível de concordância sobre conceitos relacionados a ativo, em que se utilizou a escala Likert, com 5 pontos ("concordo plenamente", "concordo simplesmente", "concordo ou discordo parcialmente", "discordo simplesmente" e "discordo totalmente"). A decisão de se utilizar a escala Likert de 5 pontos e não 7 pontos está relacionada à manutenção do instrumento de pesquisa o mais próximo possível daquele utilizado no trabalho de Goulart (2002).

A questão 2 versou sobre características do conceito de ativo. Assim, pediu-se ao respondente para assinalar quais itens da lista formariam seu conceito "ideal" de ativo, culminando em uma proxy do que seria a percepção do termo por componentes. Adicionalmente, a questão 3 versava sobre o nível de profundidade do estudo de ativo pelo respondente. Finalmente, a segunda parte da survey era composta de questões sobre características da amostra.

O questionário utilizado já fora aplicado, validado, com resultados obtidos e publicados em periódico de relevância na área contábil. Ademais, realizou-se pré-teste com 45 alunos de graduação. Indagou-se aos respondentes do pré-teste sobre dificuldades no preenchimento do questionário. Não foram observados problemas durante a execução do pré-teste. Então, prosseguiu-se a distribuição da survey.

A população pesquisada são graduandos em Ciências Contábeis. Assim, para a construção da 
amostra, optou-se por amostra por acessibilidade (conveniência). Gall, Gall e Borg (2007, p. 175, tradução nossa) argumentam: "embora uma amostra retirada aleatoriamente de uma população seja mais desejável, geralmente é melhor estudar amostra por conveniência do que não estudar nada".

A amostra foi composta por graduandos em Ciências Contábeis de cinco IES, localizadas na cidade de São Paulo, sendo uma instituição pública e quatro privadas. Complementarmente, de acordo com o Censo do Ensino Superior publicado, em 2019; no estado de São Paulo, em 2018, foram realizadas 70.527 matrículas em curso de graduação em Contabilidade, sendo 2.257 (4\%) em IES públicas e 68.000 (96\%) matrículas em escolas privadas. Portanto, os graduandos em Contabilidade estão majoritariamente concentrados na esfera privada da educação contábil (INEP, 2019). Assim, apesar da amostra ter sido colhida de maneira não probabilística, a escolha do número de IES pesquisadas está relacionada à formação do cenário da educação de nível superior no estado de São Paulo atualmente.

$\mathrm{Na}$ amostra, optou-se por discentes cursando a disciplina Teoria da Contabilidade. Tal decisão se deu por esta disciplina, em tese, promover o desenvolvimento de bagagem teórica e crítica para os estudantes se posicionarem acerca da temática pesquisada. $\mathrm{O}$ conceito de ativo integra o arcabouço tradicional da disciplina.

Adicionalmente, os dados foram coletados entre novembro e dezembro de 2016, isto é, ao final do curso de Teoria da Contabilidade. Dessa maneira, os respondentes da amostra são estudantes que, em via de regra, estiveram recentemente em contato com o conceito de ativo.

Como limitação metodológica deste estudo, a amostra do trabalho foi composta por graduandos em Contabilidade. Já a pesquisa de Goulart (2002) foi realizada com profissionais de diversas áreas de negócios (Administração, Economia, Contabilidade). Consequentemente, não é possível realizar comparação direta entre os resultados obtidos na presente pesquisa e os de Goulart (2002), porém é possível traçar perfis de tendência de comportamento, descrevendo diferenças e similaridades.

Assim, os resultados da pesquisa serão apresentados em quatro partes principais:

i) Características pessoais e perfil profissional da amostra obtida.

ii) Análise das questões sobre os conceitos de ativo e percepção sobre o nível de profundidade do estudo de ativo a partir da frequência relativa das respostas obtidas da survey, relacionando diferenças e similaridades com os resultados apresentados por Goulart (2002).

iii) Análise sobre o conceito de ativo dos respondentes da amostra, conceito formado pela lista disponível na questão 2, e, finalmente,

iv) Análise de correspondência para detectar se as questões do instrumento se associam de maneira estatisticamente significativa.

Tornou possível a confecção de mapas perceptuais, demonstrando, de forma planificada, como ocorre tal relacionamento. Escolheu-se a análise de correspondência como técnica de análise dos dados devido às "técnicas de análise de correspondência simples e múltipla permitirem considerar todo e qualquer tipo de categorias de variáveis, sem que o pesquisador precise fazer uso do incorreto procedimento de ponderação arbitrária" (FÁVERO, FÁVERO, 2017, p. 178). Assim, por este método, pode-se verificar tanto se a associação entre as variáveis é estatisticamente significativa, quanto avaliar a relação de dependências entre cada par de categorias (FÁVERO, FÁVERO, 2017).

Ademais, foi possível ordenar categorias das variáveis para melhor compreender como as respostas foram estabelecidas. Assim, foi investigada a associação entre percepção dos conceitos de ativo apresentados, e a associação da percepção do nível de profundidade dedicado ao estudo do ativo e conceitos apresentados. Finalmente, para as análises, utilizou-se nível de significância de $5 \%$.

\section{ANÁLISE E DISCUSSÃO DOS RESULTADOS}

A Tabela 1 apresenta o perfil dos respondentes, composto, majoritariamente, por estudantes de até 25 anos $(62 \%)$, sendo mais da metade (62\%) do sexo masculino. Ainda, a amostra, em sua maioria, é também formada por graduandos de IES privadas $(75 \%)$. 
Tabela 1 - Perfil dos respondentes (graduandos em Ciências Contábeis)

\begin{tabular}{|c|c|c|c|}
\hline \multicolumn{4}{|c|}{ Características Pessoais } \\
\hline Sexo & $\%$ & Faixa etária & $\%$ \\
\hline Feminino & 38 & Entre 19 e 25 anos & 62 \\
\hline Masculino & 62 & Entre 26 e 31 anos & 30 \\
\hline Instituição de Ensino & $\%$ & Entre 32 e 50 anos & 8 \\
\hline Público & 25 & & \\
\hline Privada & 75 & & \\
\hline \multicolumn{4}{|c|}{ Perfil profissional } \\
\hline Ocupação & $\%$ & Formação profissional & $\%$ \\
\hline Trabalha & 65 & Primeira graduação & 71 \\
\hline Estagia & 26 & Segunda ou mais graduações & 29 \\
\hline Estuda & 9 & Setor em qual trabalha & $\%$ \\
\hline Cursos de graduação & $\%$ & Privado & 94 \\
\hline Administração & 25 & Público & 4 \\
\hline Direito & 22 & Terceiro setor & 2 \\
\hline Economia & 15 & Tempo de experiência & $\%$ \\
\hline Engenharia & 11 & até 3 anos & 75 \\
\hline \multirow[t]{3}{*}{ Outros } & 27 & de 3 a 6 anos & 16 \\
\hline & & de 6 a 9 anos & 4 \\
\hline & & mais de 9 anos & 5 \\
\hline
\end{tabular}

Fonte: elaborado pelos autores

A faixa de experiência profissional com maior frequência é a de "até 3 anos de experiência". Ademais, a soma dos que trabalham ou estagiam é de $91 \%$, em sua maioria (94\%), no setor privado. Alguns respondentes já cursaram outras graduações anteriormente ao curso de Contabilidade. Administração e Direito foram os mais assinalados $(25 \%$ e $22 \%$, respectivamente).

\subsection{Análise das questões conceituais}

Antecipadamente às análises das questões conceituais, considerando a utilização do conceito de ativo abordado no estudo de Martins (1972) como ponto de partida, realizou-se a correspondência entre as características do conceito de ativo de Martins (1972) com as perguntas do questionário.

Portanto, a primeira pergunta refere-se à representação do termo "ativos" pela definição "bens e direitos possuídos por uma entidade". A resposta esperada seria "discordo totalmente". A segunda pergunta mencionou características dos ativos em lista disponível. Esperavam-se "benefícios futuros" como única opção assinalada. Enfim, a última questão referia-se à definição de ativos: "futuro resultado econômico que se espera obter de um agente". A resposta esperada seria "concordo totalmente".

A Figura 3 apresenta a percepção dos estudantes sobre o conceito de ativo pela ótica do significante, representando a síntese dos resultados da primeira questão.

Gráfico 1 - A definição "bens e direitos possuídos por uma entidade" reflete bem o significado do termo "ativos".

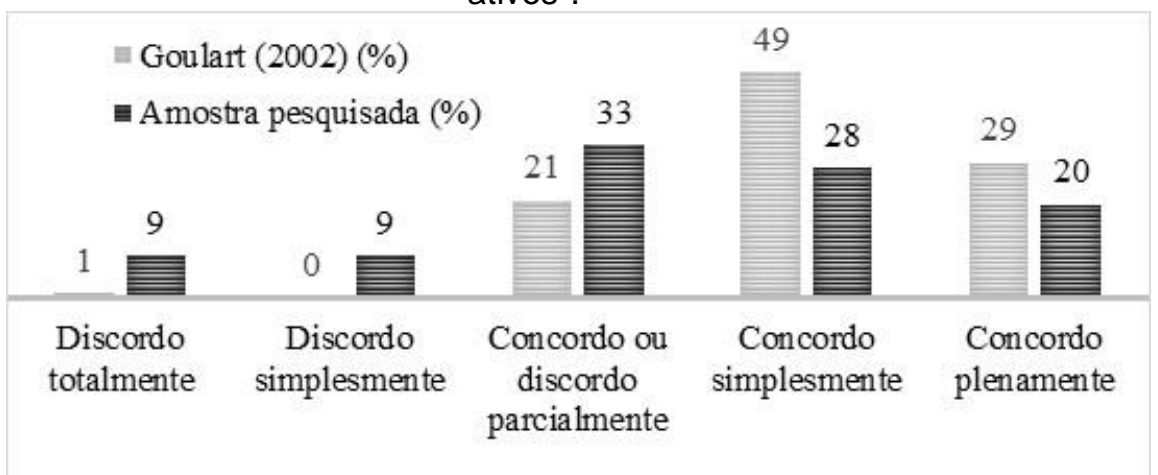

Fonte: elaborado pelos autores 
Os resultados acima apontam ligeira discordância da amostra do conceito de ativo como "bens e direitos possuídos por uma entidade" (18\%). Porém, destaca-se um cenário bastante diferente daquele obtido na pesquisa apresentada por Goulart (2002), em que o índice de discordância do conceito estava em apenas $1 \%$. Ademais, com relação aos respondentes que concordam ser o conceito de ativo bem representado por "bens e direitos", representam menos de metade da amostra (48\%). Já, no estudo de Goulart (2002), este índice se apresentava em $78 \%$ da amostra verificada. A amostra atual ainda tende a concordar com o conceito baseado no significante, porém, em relação ao estudo de Goulart (2002), a tendência de percepção entre as duas amostras é majoritariamente discrepante.

A Figura 4 evidencia a percepção da amostra sobre a pergunta 4, que faz referência ao conceito de "ativo" a partir da construção ideológica de ativo por meio do significante. $64 \%$ da amostra concorda ser o conceito de "ativo" bem representado por "futuro resultado econômico que se espera obter de um agente". Apenas $9 \%$ discordam do conceito. Isso pode indicar que a amostra pesquisada tende a compreender 0 conceito de "ativo" segundo seu significado.

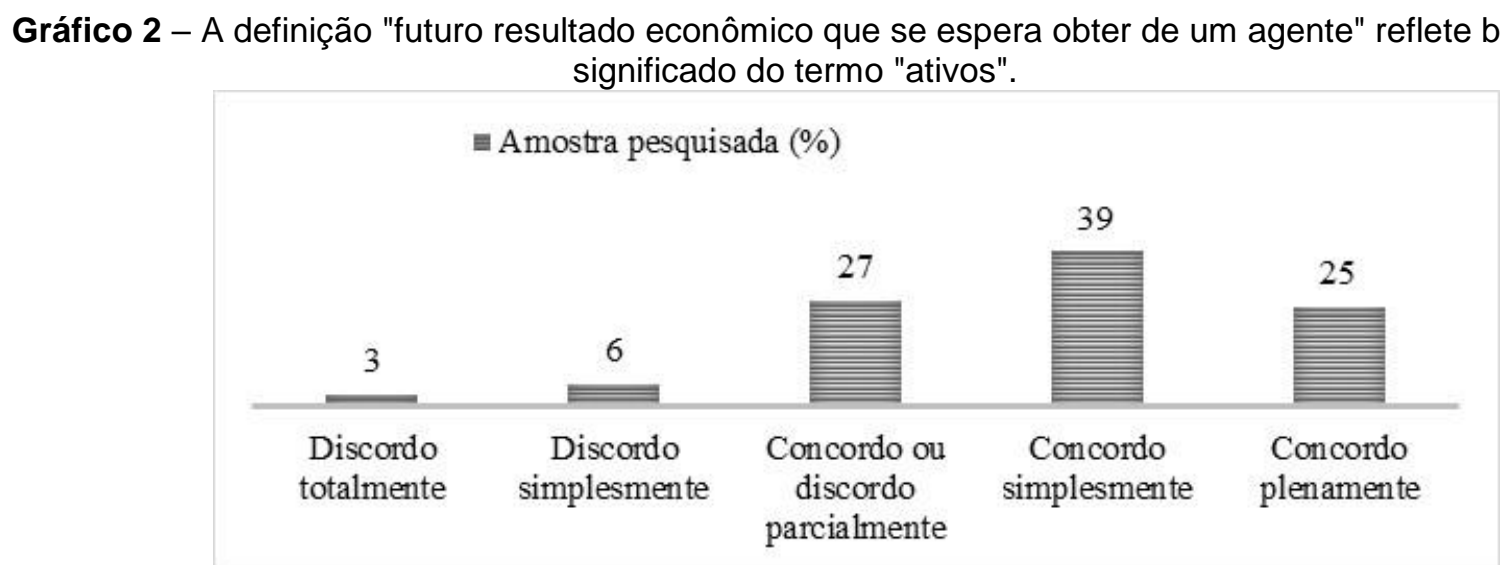

Fonte: elaborado pelos autores

Outro possível fator influenciador na percepção estudantil é a convergência do Brasil às normas contábeis internacionais. A partir delas, será necessário que o profissional exerça seu julgamento profissional em sua rotina diária. Como uma das mudanças advindas do processo de convergência, é a Contabilidade baseada em princípios, na qual o contador não é mais instruído sobre "como fazer", mas lhe são dadas ferramentas para "o que deve ser feito" conforme sua realidade. Assim, prevalece a essência econômica das transações sobre a norma jurídica.

Outra possível motivação para a diferença entre as percepções nas amostras relatadas são livros orientadores para a profissão, como o Manual de Contabilidade, editado pela Fundação Instituto de Pesquisas Contábeis, Atuariais e Financeiras (FIPECAFI). A obra reúne direcionamentos técnicos e discussões contábeis, cujo conteúdo é vastamente utilizado pelos contadores em diversos níveis de formação. Assim, no ano 2000, o Manual de Contabilidade conceituava "ativo": "compreende as aplicações de recursos, normalmente em bens e direitos" (MARTINS, GELBCKE, IUDíCIBUS, 2000). Este fator pode ter influenciado a realidade da amostra de Goulart (2002).

Destaca-se, ainda, que à época da coleta dos dados da presente pesquisa, o conceito de ativo disponível no Manual de Contabilidade societária da FIPECAFI apresentava "ativo" como sendo um conceito que "compreende os recursos controlados por uma entidade e dos quais se esperam benefícios econômicos futuros" (MARTINS et al., 2013). Esta pode ser uma razão para mudanças na percepção entre as amostras analisadas.

A disparidade entre as duas amostras traz, também, a construção social do significado das palavras, ocorrendo em uma comunidade histórica e socialmente localizada (MACINTOSH, 2002). Nesse caso, os autores acima citados, autores do Manual de Contabilidade, são parte desta comunidade. 
Gráfico 3 - Percepção dos estudantes sobre seu nível de reflexão sobre o conceito de ativo.

\begin{tabular}{|c|c|c|c|c|c|c|c|}
\hline \multirow[b]{2}{*}{16} & \multirow[t]{2}{*}{65} & 46 & \multicolumn{2}{|c|}{ E Goulart (2002) (\%) } & \multicolumn{3}{|c|}{ Emostra pesquisada (\%) } \\
\hline & & & 22 & 21 & & 17 & 11 \\
\hline \multicolumn{2}{|c|}{ Com profundidade } & \multicolumn{2}{|c|}{$\begin{array}{l}\text { De maneira um tanto } \\
\text { superficial }\end{array}$} & $\begin{array}{l}\text { Ainda nã } \\
\text { oportu }\end{array}$ & $\begin{array}{l}\text { ve tal } \\
\text { de }\end{array}$ & \multicolumn{2}{|c|}{$\begin{array}{l}\text { Já tive a oportunidade, mas } \\
\text { não sei se com profundidade } \\
\text { ou de maneira superficial }\end{array}$} \\
\hline
\end{tabular}

\section{Fonte: elaborado pelos autores}

Os resultados obtidos em relação a Goulart (2002) não são surpreendentes. Como a amostra desta pesquisa conteve exclusivamente futuros contadores, enquanto a pesquisa de Goulart tratou da área de negócios como um todo, seria, então, de se esperar um maior número de respondentes que julgam ter tido a oportunidade de discutir e refletir sobre o conceito de ativo ao longo do curso. Esses dados mostram estudantes (apenas $2 \%$ dizem não ter tido oportunidade) que tiveram oportunidade de explorar o conceito de ativo ao longo do curso.

\subsection{Análise da conceituação de ativo}

A questão 2 elencava uma lista de atributos para os respondentes assinalarem as características que descreveriam o conceito de ativo. A Figura 6 apresenta os resultados obtidos.

Gráfico 4 - Se você formular uma definição do conceito contábil de ativos, quais três termos que você necessariamente incluiria (por representarem características essenciais dos ativos)?

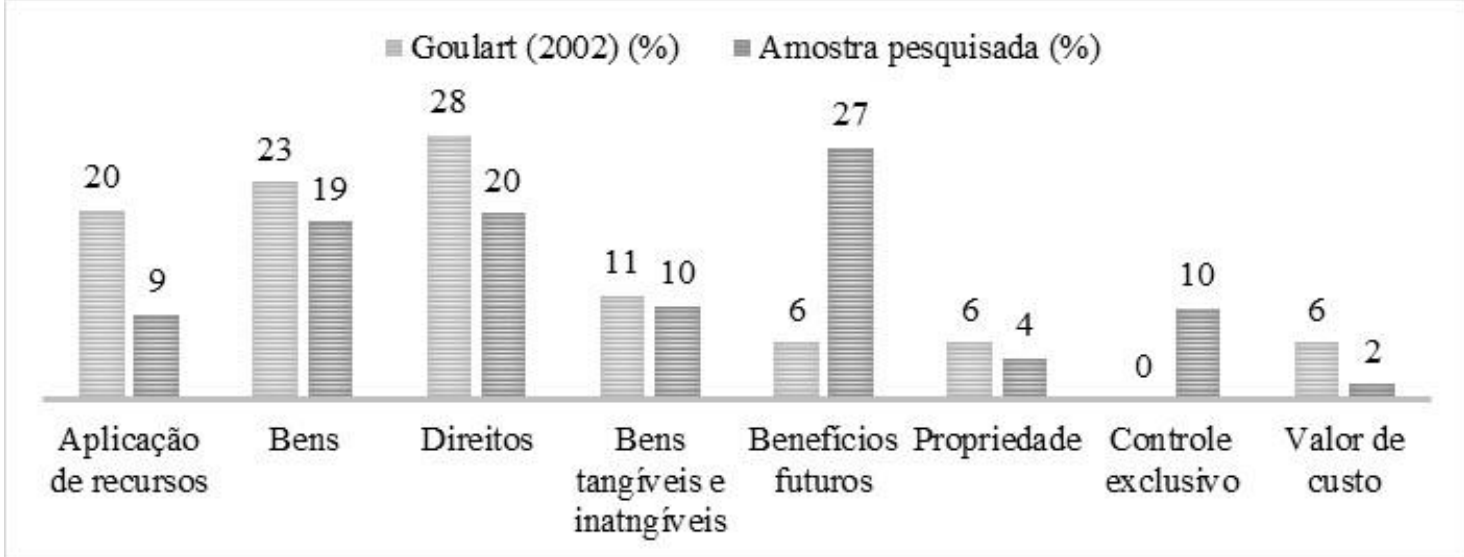

Fonte: elaborado pelos autores

Os resultados apontam que, tanto na amostra coletada no estudo de Goulart (2002) quanto na amostra atual, os itens "bens" e "direitos" aparecem de forma marcante (vale ressaltar novamente que, apesar de não ser possível comparar diretamente as duas amostras, pode-se comentar diferenças e similaridades). Porém, as categorias "bens" e "direitos" não configuram condições ontológicas ligadas ao termo "ativo". Isto é, detecta-se, neste ponto, confusão nos dados analisados entre conceitos de significado e significante.

De acordo com Saussure (2006), a língua é formada por um sistema de signos, e estes são formados por significantes e significados. Assim, significante seria a imagem acústica do signo, percebido como "está não é o som material, coisa puramente física, mas a impressão (empreinte) psíquica desse som, a representação que nos dá o testemunho de nossos sentidos" (SAUSSURE, 2006, p. 80). Já o significado é a parte inteligível do signo (SAUSSURE, 2006). Assim, o significado seria o conceito abstrato que dá origem ao ativo e o significante, aquilo que exemplifica o ativo em si.

Então, questionou-se aos respondentes o significado do termo ativo (resposta esperada "benefícios futuros" segundo MARTINS, 1972), e obteve-se, majoritariamente, respostas relacionadas ao significante (bens e direitos). Este resultado nas duas amostras ainda tende a reforçar a hipótese proposta por Goulart (2002) de que o conhecimento tanto de profissionais quanto de estudantes de Contabilidade pode ainda ser superficial. Também, o entendimento do próprio termo "conceito" pode revelar-se problemático. Adicionalmente, os cursos de graduação pesquisados podem não estar conduzindo adequadamente o ensino 
do conceito de ativo. Também, é possível que tenha havido problemas de elaboração ou de interpretação da pergunta. Todas essas possíveis razões apontam para a existência de questões a serem exploradas para melhorar o ensino do conceito de ativo. É necessário buscar novas abordagens no processo de ensino/aprendizagem para melhoria constante na educação.

Aglutinaram-se os resultados da questão 2 para observar qual seria o conceito de ativo mais repetido na amostra da pesquisa (Tabela 2). Apresentaram-se os cinco conceitos mais votados. Assim, o conceito de ativo mais repetido é: "bens", "direitos" e "benefícios futuros", em segundo lugar, "aplicação de recursos" "benefícios futuros" e "controle exclusivo".

Tabela 2 - Aglutinação de características para formação do conceito de ativo

\begin{tabular}{|c|c|c|c|}
\hline $\begin{array}{c}\text { № de } \\
\text { respondentes }\end{array}$ & Característica 1 & Característica 2 & Característica 3 \\
\hline 51 & Bens & Direitos & Benefícios futuros \\
\hline 15 & Aplicação de recursos & Benefícios futuros & Controle exclusivo \\
\hline 13 & Bens & Direitos & $\begin{array}{c}\text { Bens tangíveis e } \\
\text { intangíveis }\end{array}$ \\
\hline 10 & Direitos & $\begin{array}{l}\text { Bens tangíveis e } \\
\text { intangíveis }\end{array}$ & Benefícios futuros \\
\hline 10 & $\begin{array}{l}\text { Bens tangíveis e } \\
\text { intangíveis }\end{array}$ & Benefícios futuros & Controle exclusivo \\
\hline
\end{tabular}

Fonte: elaborado pelos autores

O conceito de ativo mais votado pelos respondentes demonstra a percepção da amostra do ativo segundo seu significado. Porém, ainda reproduz definições clássicas baseadas no significante, conforme a Teoria do Signo. Este resultado pode indicar mudanças graduais no processo de ensino da Contabilidade.

Destaca-se não ser característica intrínseca para existência do ativo o "controle exclusivo". Este é observado no processo de reconhecimento de ativos por uma entidade. No tripé da Contabilidade (evidenciação, mensuração e divulgação) ou ainda no "processo contábil", é preciso que sejam identificados os ativos das entidades, é nesse momento que "controle exclusivo" é importante. Porém, para a caracterização do conceito de ativo, do que é o ativo "puro", o determinante "controle exclusivo" não é, ontologicamente falando, uma característica demandante para a existência do ativo.

O terceiro conceito de ativo mais votado ("bens", "direitos" e "bens tangíveis e intangíveis") reforça a confusão entre significado e significante, dado que conceito remete a significado, e os respondentes assinalaram apenas significantes.

\subsection{Análise de correspondência}

O intuito da análise de correspondência é identificar se a associação entre as variáveis categóricas é ou não estatisticamente significativa. Assim, analisando-se teste Chi-Quadrado, com nível de significância de $5 \%$, é possível constatar "se a distribuição de frequências das categorias de uma variável segundo as categorias da outra variável é aleatória ou se há um padrão de dependência entre as duas" (FÁVERO, FÁVERO, 2017, p. 182). A tabela 3 expõe os resultados obtidos para o teste Chi-Quadrado.

Tabela 3 - Teste Chi-Quadrado

\begin{tabular}{|c|c|c|c|c|}
\hline Tipo & Questão & $\begin{array}{c}\text { Q1 - } \\
\text { Conceito } \\
\text { bens e } \\
\text { direitos }\end{array}$ & $\begin{array}{l}\text { Q3 - Profundidade } \\
\text { Estudo ativo }\end{array}$ & $\begin{array}{c}\text { Q4 - Conceito } \\
\text { Benefícios } \\
\text { econômicos } \\
\text { futuros }\end{array}$ \\
\hline \multirow{3}{*}{ Qualificadoras } & Gênero & 0,254 & 0,029 & 0,044 \\
\hline & Trabalha/Estuda & 0,253 & 0,929 & 0,079 \\
\hline & Instituição & 0,023 & 0,19 & 0,000 \\
\hline \multirow{3}{*}{ Conceituais } & Q1 - Conceito bens e direitos & - & 0,019 & 0,018 \\
\hline & $\begin{array}{c}\text { Q3 - Profundidade } \\
\text { Estudo ativo }\end{array}$ & 0,019 & - & 0,199 \\
\hline & $\begin{array}{l}\text { Q4 - Conceito Benefícios } \\
\text { econômicos futuros }\end{array}$ & 0,018 & 0,199 & - \\
\hline
\end{tabular}

Fonte: elaborado pelos autores 
A análise do teste chi-quadrado demonstra que existe associação perceptiva significativa em relação ao conceito de "ativo" e o gênero dos respondentes, bem como em relação à instituição frequentada por eles. Os resultados também foram significantes para as questões conceituais. A seção seguinte apresenta os mapas perceptuais.

Um mapa perceptual é um diagrama que demonstra como as categorias se associam no plano. Assim, primeiro conduz-se o teste Chi-Quadrado para verificar a significância da associação entre as variáveis, par a par, para depois determinar cargas inerciais que irão direcionar entre linhas e colunas como se dará a orientação de cada carga inercial no plano ou mapa perceptual.

Então, conforme fora realizada a relação ao que seria a resposta esperada do questionário distribuído, é possível traçar o que seria um mapa ideal, em que a opção de resposta da questão 1 "discordo totalmente" estaria próxima da opção de resposta da questão 4, "concordo totalmente", sendo a opção de resposta da questão 3, "com profundidade". Isto é, o mapa perceptual ideal seria aquele com discordância do conceito que prioriza o significante do ativo, portanto reconhece seu significado e percebe dedicação profunda ao tema de estudo.

O mapa perceptual, obtido a partir dos dados apresentados na figura 7 , demonstra a associação entre as questões 1 e 3 . Não foi obtida relação entre as questões 3 e 4, como seria esperado.

Gráfico 5 - Mapa perceptual conceito ativo (bens e direitos - significante) x percepção da profundidade do estudo

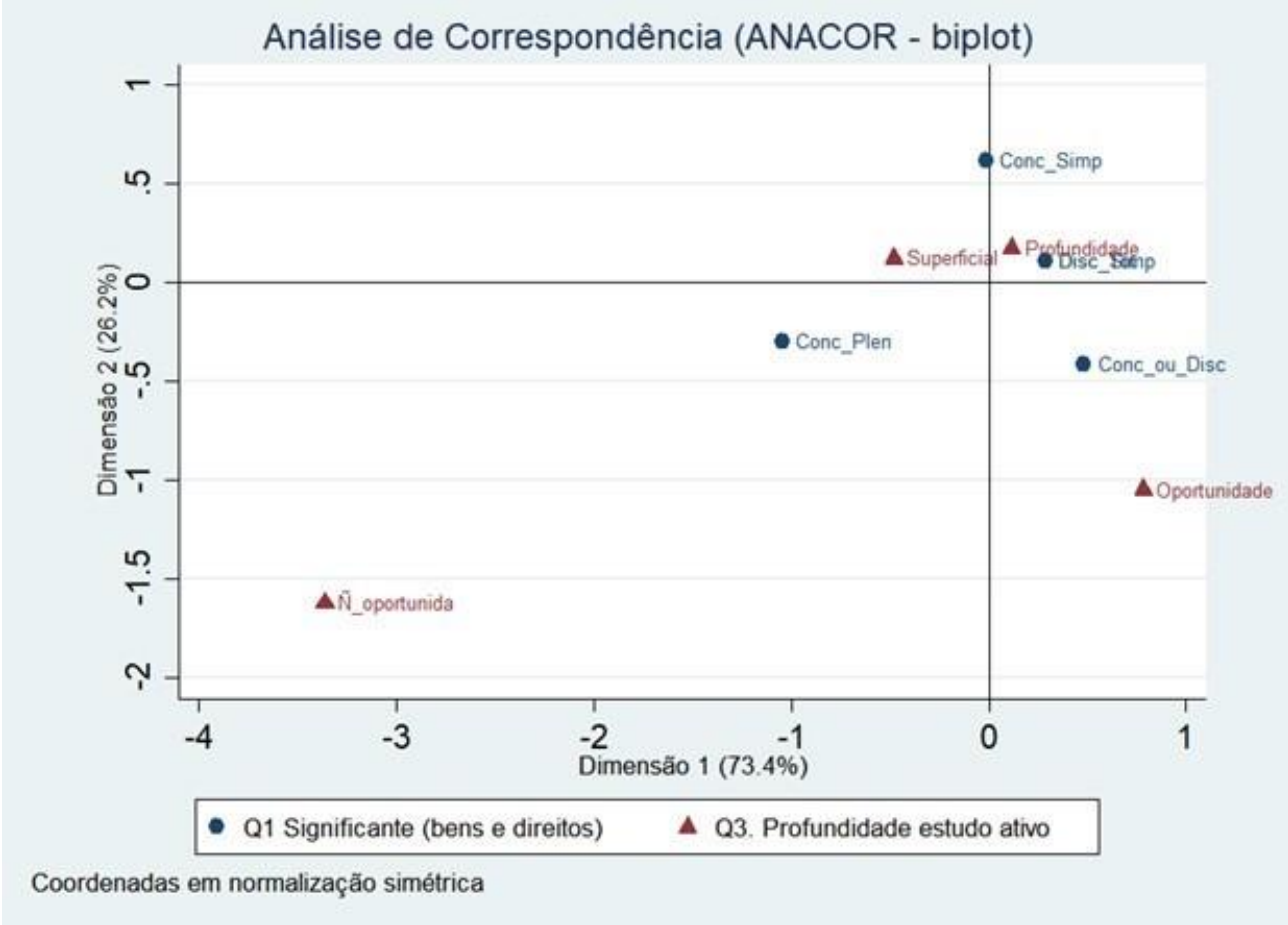

Fonte: elaborado pelos autores

O mapa demonstra que a associação mais próxima ocorre entre aqueles que "discordam simplesmente" que o termo "ativo" pode ser representado por "bens e direitos que uma entidade possui" e, ainda, são os respondentes que assinalaram terem se dedicado profundamente ao tema. Enquanto isso, aqueles que assinalaram conhecerem o tema superficialmente estão mais próximos das categorias "discordar simplesmente", "concordar simplesmente" e "concordar plenamente" com a expressão "bens e direitos que uma entidade possui" para caracterização de ativo.

Com pouco tempo de estudo do conceito de ativo, alguns estudantes podem ter a percepção de possuírem um entendimento razoável do conceito em questão e responderem que discordam do disposto na questão 1, enquanto outros que não compreenderam tão bem o conceito poderiam assim concordar (seja plenamente ou simplesmente) com a expressão proposta. Assim, não causa estranhamento respondentes com percepção de estudo aprofundado do tema terem padrão de resposta errático.

Em contrapartida, o resultado obtido daqueles que autodeclararam terem estudado de maneira aprofundada o conceito de ativo é contraintuitivo, visto que tais estudantes tenderiam a manifestar discordância plena sobre o conceito de ativo ser "bens e direitos". Tal resultado sugere a detecção do fenômeno conhecido como Dunning-Kruger, em que pessoas com baixa performance, em determinada tarefa, costumam superestimar suas habilidades, enquanto indivíduos que tiveram uma boa performance tendem a 
subestimar suas habilidades (KRUGER; DUNNING, 1999; BOZ; KOC, 2019).

Ademais, tal achado se encontra alinhado à teoria saussureana (SAUSSURE, 2006), visto que, mesmo se aprofundando nos estudos sobre ativo, esses estudantes ainda não conseguem distinguir propriamente seu conceito. Isto se deve à escrita confundir-se com a imagem que já têm de ativo através dos anos, como palavra falada, roubando do conceito de ativo seu papel fundamental. Mesmo em pesquisas, com conceito descrito, a representação recebe maior importância do que o próprio signo.

\section{CONSIDERAÇÕES FINAIS}

Este estudo contribuiu para a ampliação da discussão da educação contábil trazendo à tona relevante tema, o conceito de "ativo". Não foi objetivo exaurir o tema, mas sim revelar questões reflexivas acerca do ensino contábil.

Dessa forma, este trabalho analisa a percepção de estudantes graduandos em Ciências Contábeis acerca do conceito de ativo e seus componentes. Fundamentou-se a pesquisa no estudo dos conceitos, pela Teoria do Signo Linguístico de Saussure, aprofundando discussão sobre significado e significante. Adicionalmente, analisaram-se conceitos históricos de ativo, compreendendo-se o processo de mudança no seu significado, assim como a convergência às normas internacionais de Contabilidade.

Através das análises, constatou-se a existência de confusão relacionada ao conceito de ativo entre significado e significante, sob perspectiva da Teoria do Signo Linguístico de Saussure. Isso causa entendimento superficial do conceito de ativo, podendo trazer falhas no processo de aprendizagem dos demais conceitos contábeis e suas aplicações, reforçando resultados encontrados por Goulart (2002).

Destaca-se, ainda, que, apesar de corroborar os achados de pesquisa de Goulart (2002), os resultados deste trabalho sugerem maior importância à característica "benefícios econômicos futuros" na opinião dos estudantes participantes da pesquisa. Outrossim, os resultados da ANACOR apontam que a relação entre a questão 1 do questionário (conceito de ativo - significante) e o nível de profundidade do estudo do ativo é estatisticamente significativa. Ademais, os estudantes que indicam terem estudado com maior profundidade o tema analisado estão localizados no mapa perceptual produzido em um local próximo daqueles que discordam que o conceito de ativo é bem representado por "bens e direitos possuídos por uma entidade".

Este trabalho contribui para a pesquisa e para a educação contábil no contexto brasileiro. A pesquisa, no sentido de indicar mudanças significativas em relação à realidade pesquisada por Goulart (trabalho ponto de partida), capta mudanças ocorridas ao longo do tempo na percepção da amostra pesquisada. Já para a formação de contadores, os achados deste estudo evidenciam desafios ao aprimoramento no processo de ensino-aprendizagem de conceito basilar na formação de um profissional de excelência em Contabilidade.

Por fim, destaca-se que, embora haja evolução histórica e socialmente concebida, ainda temos futuros contadores tratando coisas diferentes com nomes iguais. Sendo possíveis consequências deste achado a formação deficiente do bacharel em Ciências Contábeis, deficiência que vai de encontro ao perfil do profissional contador que atua num ambiente onde vigoram as Normas Internacionais de Contabilidade e que, por sua vez, há a prevalência da essência econômica sobre a forma jurídica. Nesse sentido, um contador com formação débil em conceito basilar, em sua área de atuação, poderá incorrer em avaliação e julgamentos tanto superficiais quanto equivocados. Por fim, ainda é possível que esse resultado detectado pelo estudo possa influenciar o sucesso profissional do estudante, bem como causar ruídos em toda a classe contábil. Assim, normalizar a compreensão dos conceitos em Contabilidade faz parte também do seu fortalecimento enquanto Ciências Sociais Aplicadas.

Recomenda-se, para pesquisas futuras, a replicação longitudinal do estudo para verificar a percepção estudantil, de docentes e de profissionais. Sugerem-se estudos fenomenográficos para compreender a concepção de ativos de docentes e discentes. Por fim, sugere-se a adoção de outros aportes teóricos - como Teoria da Aprendizagem Significativa - para explicar a compreensão superficial do conceito de ativo pelos graduandos.

\section{REFERÊNCIAS}

ANTHONY, R. N. Management accounting principles. London: R. D. Irwin, 1970.

BORBA, J. A.; POETA, F. Z.; VICENTE, E. F. R. Teoria da contabilidade: uma análise da disciplina nos programas de mestrado brasileiros. Sociedade, Contabilidade e Gestão, v. 6, n. 2, pp. 124-138, 2011. Disponível em: $<$ https://doi.org/10.21446/scg ufri.v6i2.13242>. Acesso em: 02 jun. 2021.

BOZ, H.; KOC, E. Service quality, emotion recognition, emotional intelligence and Dunning Kruger syndrome. Total Quality Management \& Business Excellence, pp. 1-14, 2019. Disponível em: $<$ https://doi.org/10.1080/14783363.2019.1686971>. Acesso em: 02 jun. 2021.

CANNING, J. B. The economics of accountancy: a critical analysis of accounting theory. New York: The Ronald Press 
Company, 1929.

CARVALHO, C. Para compreender Saussure: fundamentos e visão crítica. 20. ed. Petrópolis, RJ: Vozes, 2013. COLLADO, A. J. Fundamentos de Linguística Geral. Lisboa: Edições 70, 1980.

CUNHA, L. C.; GUIDINI, A.; KLANN, R. C. A Disciplina de Teoria da Contabilidade e a Convergência às Normas Internacionais de Contabilidade: Percepção dos Professores dos Programas de Pós-Gradução Stricto Sensu em Contabilidade. Pensar Contábil, v. 19, n. 68, 2017. Disponível em: <http://www.atena.org.br/revista/ojs-2.2.306/index.php/pensarcontabil/article/view/3046>. Acesso em: 02 jun. 2021.

D'AURIA, F. Contabilidade: Noções Preliminares. São Paulo: Atlas, 1958.

DANTAS, J. A.; RODRIGUES, F. F.; NIYAMA, J. K.; MENDES, P. C. de M. Normatização contábil baseada em princípios ou em regras?: Benefícios, custos, oportunidades e riscos . Revista de Contabilidade e Organizações, [S. I.], v. 4, n. 9, p. 3-29, 2010. DOI: 10.11606/rco.v4i9.34765. Disponível em: $<$ https://www.revistas.usp.br/rco/article/view/34765 >. Acesso em: 13 jun. 2021.

DEELY, J. Basics of Semiotics. Bloomington: Indiana University Press, 1990.

DILLARD, J.; VINNARI, E. Critical dialogical accountability: From accounting-based accountability to accountabilitybased accounting. Critical Perspectives on Accounting, v. 62, pp. 16-38, 2019. Disponível em: <https://doi.org/10.1016/j.cpa.2018.10.003>. Acesso em: 02 jun. 2021.

DUBOIS, J.; GIACOMO, M. ; GUESPIN, L.; MARCELLESI, C.; MARCELLESI, J. B ; MEVEL, J. P. Dicionário de Lingüística. Tradução de Frederico Pessoa de Barros, Gesuína Domenica Ferretti, John Robert Schmitz, Leonor Scliar Cabral, Maria Elizabeth Leuba Salum e Valter Khedi. São Paulo: Cultrix, 1998.

FÁVERO, L.; FÁVERO, P. Análise de dados: técnicas multivariadas exploratórias com SPSS e STATA. Rio de Janeiro: Campus-Elsevier, 2017.

GALL, M. D.; GALL, J. P.; BORG, W. R. Collecting research data with questionnaires and interviews. In: GALL, M. D.; GALL, J. P.; BORG, W. R. Educational research: An introduction. Boston: Pearson/Allyn \& Bacon, 2007, pp. $227-261$.

GOULART, A. M. C. O conceito de ativos na contabilidade: um fundamento a ser explorado. Revista Contabilidade \& Finanças, v. 13, n. 28, pp. 56-65, 2002. Disponível em: <https://www.revistas.usp.br/rcf/article/view/34068>. Acesso em: 02 jun. 2021.

IASB. International Accounting Standards Board. Conceptual framework for Financial Reporting 2018. London: IFRS, [2018?]. Disponível em: <https://www.ifrs.org/projects/completed-projects/2018/conceptual-framework/\#publisheddocuments $>$. Acesso em: 02 jun. 2021.

INEP. Instituto Nacional de Estudos e Pesquisas Educacionais Anísio Teixeira. Sinopse Estatística do Ensino Superior. Brasília: Inep, 2019. Disponível em: <http://inep.gov.br/sinopses-estatisticas-da-educacao-superior>. Acesso em: 02 jun. 2021.

IUDICIBUS, S. Teoria da Contabilidade. 6. ed. São Paulo: Atlas, 2000.

IUDICIBUS, S.; BEUREN, I. M.; DOS SANTOS, V. Ensino da Teoria da Contabilidade nos programas de pós-graduação de Ciências Contábeis do Brasil. Revista Universo Contábil, Blumenau, v. 12, n. 4, pp. 6-29, 2016. Disponível em: <https://www.redalyc.org/pdf/1170/117049458002.pdf>. Acesso em: 02 jun. 2021.

KRUGER, J.; DUNNING, D. Unskilled and unaware of it: How difficulties in recognizing one's own incompetence lead to inflated self-assessments. Journal of Personality and Social Psychology, v. 77, n. 6, pp. 1.121-1.134, 1999. Disponível em: <https://pubmed.ncbi.nlm.nih.gov/10626367/>. Acesso em: 02 jun. 2021.

LOPES, A. B. A informação contábil e o mercado de capitais. São Paulo: Pioneira Thomson Learning, 2002. HENDRIKSEN, E. S.; VAN BREDA, M. F. Teoria da contabilidade. Tradução de Antonio Zoratto Sanvicente. São Paulo: Atlas, 2012.

LIMA FILHO, R. N.; BRUNI, A. L. Percepção dos graduandos em Ciências Contábeis de Salvador (BA) sobre os conceitos relevantes da Teoria da Contabilidade. Revista de Educação e Pesquisa em Contabilidade (REPeC), v. 6 , n. 2, pp. 187-203, 2012. Disponível em: <http://www.repec.org.br/repec/article/view/176/609>. Acesso em: 02 jun. 2021.

MACINTOSH, N. B. Accounting, accountants and accountability. Poststructuralist positions. London: Routledge, 2002.

MARTINEZ, A. L.; FLORES, E.; MACIEL, F.; SOUZA, N. A. Ativo e sua mensuração. In: FLORES, E.; BRAUNBECK, G. O.; CARVALHO, L. N. G. D. (Orgs.). Teoria da Contabilidade Financeira: fundamentos e aplicações. São Paulo: Atlas, 2017, pp. 107-136.

MARTINS, E. Contribuição à avaliação do ativo intangível. Tese (Doutorado em Contabilidade) - Faculdade de Economia, Administração e Contabilidade da Universidade de São Paulo (USP), São Paulo, 1972, versão impressa. MARTINS, E.; GELBCKE, E. R.; IUDíCIBUS, S. Manual de Contabilidade das Sociedades por Ações. São Paulo: Atlas, 2000.

MARTINS, E.; GELBCKE, E. R.; SANTOS, A. DOS; IUDÍCIBUS, S. de. Manual de contabilidade societária: aplicável a todas as sociedades: de acordo com as normas internacionais e do CPC. São Paulo: Atlas, 2013.

MEIGS, W. B.; JOHNSON, C. E. Accounting - The Basis for Business Decisions. New York: McGraw-Hill, 1962. 
PATON, W. A. Accounting. Macmillan, 1924.

PICCOLI, M. R.; CHIARELLO, T. C.; KLANN, R. C. A percepção dos acadêmicos sobre conceitos abordados na disciplina de Teoria da Contabilidade. Revista de Gestão, Finanças e Contabilidade, v. 5, n. 1, pp. 40-57, 2015. Disponível em: <https://www.revistas.uneb.br/index.php/financ/article/view/735/736>. Acesso em: 02 jun. 2021.

ROBERTS, J.; WANG, T. Faithful representation as an 'objective mirage': A Saussurean analysis of accounting and its participation in the financial crisis. Critical Perspectives on Accounting, v. 65, 2019. Disponível em: <https://doi.org/10.1016/j.cpa.2019.02.005>. Acesso em: 02 jun. 2021.

SANTOS, L. P. G.; FREITAS, S. C.; DIAS FILHO, J. M. Aprendizado de Contabilidade e a percepção do conceito de lucro: um estudo exploratório. Revista de Educação e Pesquisa Em Contabilidade (REPeC), v. 14, n. 1, pp. 78-99, 2020. Disponível em: <http://www.repec.org.br/repec/article/view/2479>. Acesso em: 02 jun. 2021.

SAUSSURE, F. Curso de linguística geral. São Paulo: Cultrix, 2006.

SOUZA, F. F.; VICENTE, E. F. R. Compreensão dos Graduandos dos Cursos de Ciências Contábeis Quanto aos Conceitos Relevantes Ensinados na Disciplina de Teoria da Contabilidade em IES da Grande Florianópolis. Revista de Educação e Pesquisa em Contabilidade, v. 11, n. 1, pp. 110-126, 2017. Disponível em:

<https://doi.org/10.17524/repec.v11i1.1450>. Acesso em: 02 jun. 2021.

SPROUSE, R. T; MOONITZ, M. Tentative set of broad accounting principles for business enterprises. Accounting research study $n^{\circ} 03$. Guides, Handbooks and Manuals 149. Oxford: University of Mississippi, 1962. 
